\title{
Controlling the Film Microstructure in Organic Thermoelectrics
}

\author{
Miao Xiong ${ }^{a}$ (i) \\ Jie-Yu Wang ${ }^{a}$ (D) \\ Jian Pei ${ }^{* a}$ (i) \\ a College of Chemistry and Molecular Engineering, Peking University, Beijing 100871, \\ China \\ jianpei@pku.edu.cn
}

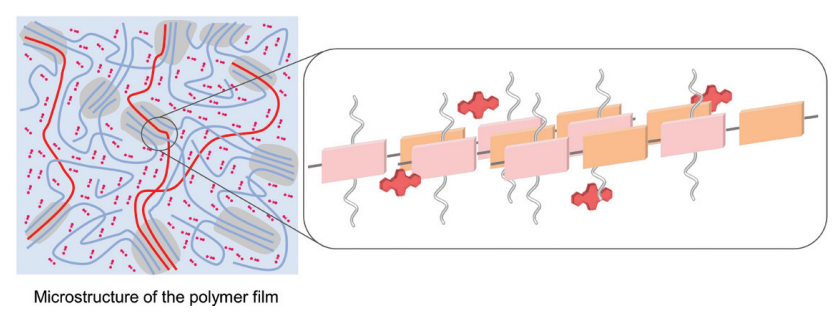

wearable devices. ${ }^{4}$ In the past few years, a range of polymers with high thermoelectric performance have been developed. The p-type polymer poly(3,4-ethylenedioxythiophene) (PEDOT) has exhibited a high thermoelectric figure of merit $(z T)$ over 0.4 , which is comparable to those of inorganic materials at low temperature, making polymeric thermoelectrics particularly suitable for applications. ${ }^{5}$ To realize impactful thermoelectrical device architectures, both p- and n-type polymer materials with high thermoelectrical performance are needed. Compared to high-performance p-type polymers, n-type polymers still lag far behind. Therefore, we put more focus on n-type polymers.

The performance of OTE materials can be evaluated by the figure of merit $(z T)$, which can be expressed as

$$
z T=\frac{S^{2} \sigma T}{\kappa}
$$

where $S, \sigma, k$, and $T$ are the Seebeck coefficient, electrical conductivity, thermal conductivity, and temperature, respectively. The conductivity $(\sigma=n \mu q)$ is related to the carrier concentration $(n)$, the carrier mobility $(\mu)$, and the electron charge parameter $(q)$. Due to the challenge in measuring thermal conductivity of organic semiconductor materials, the performance of OTEs is usually evaluated by the power factor $\left(\mathrm{PF}=S^{2} \sigma\right)$. To achieve high $\mathrm{PF}$, both high $\sigma$ and high $S$ should be satisfied. However, $\sigma$ and $S$ are strongly interrelated and conflict with each other. It is still a significant challenge to optimize PF.

Recently, some strategies have been developed to improve the thermoelectric performance, such as introducing nanoparticles ${ }^{6}$ or inorganic materials ${ }^{7}$ with high conductivity or Seebeck coefficient to the polymer matrix. For the conjugated polymers with wide bandgaps, a widely used method to optimize the thermoelectrical performance is to introduce organic molecular dopants, which have better miscibility with polymers and good solution processability. The introduced dopants can increase additional charge carriers by reducing or oxidizing the polymers. However, the phase separation of polymers and dopants will impede the sufficient loading of dopants and prevent a further increase in charge carrier concentration. The distribution of dopant ions within 


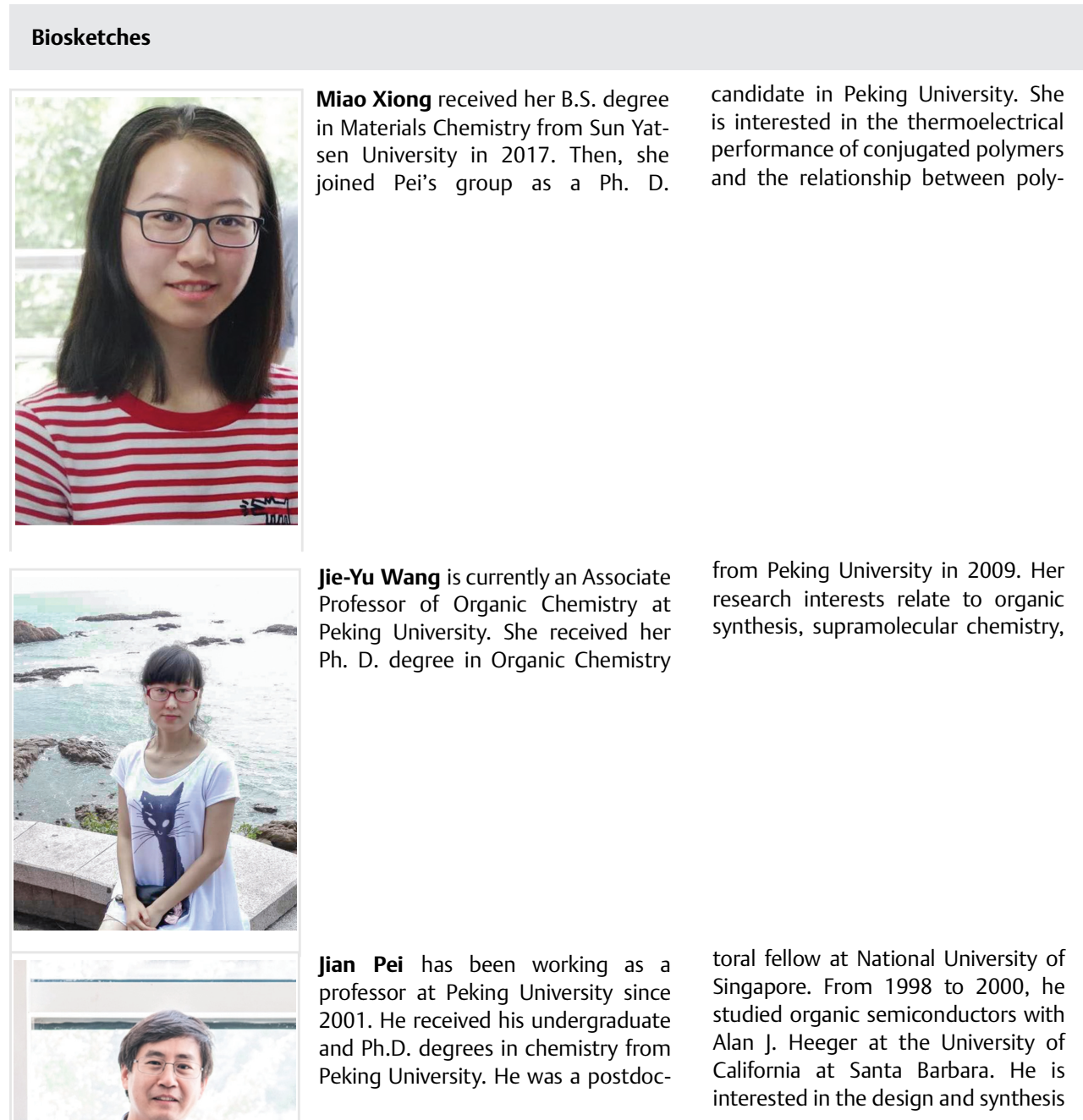

and the fabrication of organic nano/micromaterials.

the polymer films can influence the film structure in the micro- and macro-scale, thus affecting the final electrical and thermoelectrical performances.

Optimizing the film microstructure is crucial and challenging for improving the thermoelectric performance. For example, the $z T$ value of PEDOT:PSS, a classic and highperformance organic polymer, can be improved over 0.2 when replacing the PSS with ethylene glycol or DMSO. ${ }^{5}$ Rearranging the distribution of the PEDOT and PSS can tune the degree of doping and obtain a higher performance. Many studies have been reported on the regulation of the distribution of PSS within the PEDOT film and the crystallinity to optimize the microstructure and performance. ${ }^{8}$ However, the microstructure modulation of a heterogeneous two-phase system is far more difficult than the microstructure control of the pure mer aggregation behavior and electrical performance.

\begin{abstract}
and the structure-property relationship of organic semiconductors for optoelectronic devices.
\end{abstract}

polymer, because the different properties of polymers and dopants as well as the interactions of both components must be considered. ${ }^{9}$

The film microstructure includes the surface appearance, also called morphology, the interchain and intrachain packing of the polymer, as well as the binding sites of dopants and polymers. ${ }^{10}$ It is important to figure out the details of the film microstructure because the packing of neighboring chains and connectivity of the domains determine the mobility and the path taken by charge carriers through the film after doping. ${ }^{11}$ The region and status of dopants spatially existing in polymer films have a pivotal influence on the morphology, thus affecting the electrical performance. In this review, we discuss the morphology change in films after introducing dopants. 
a)

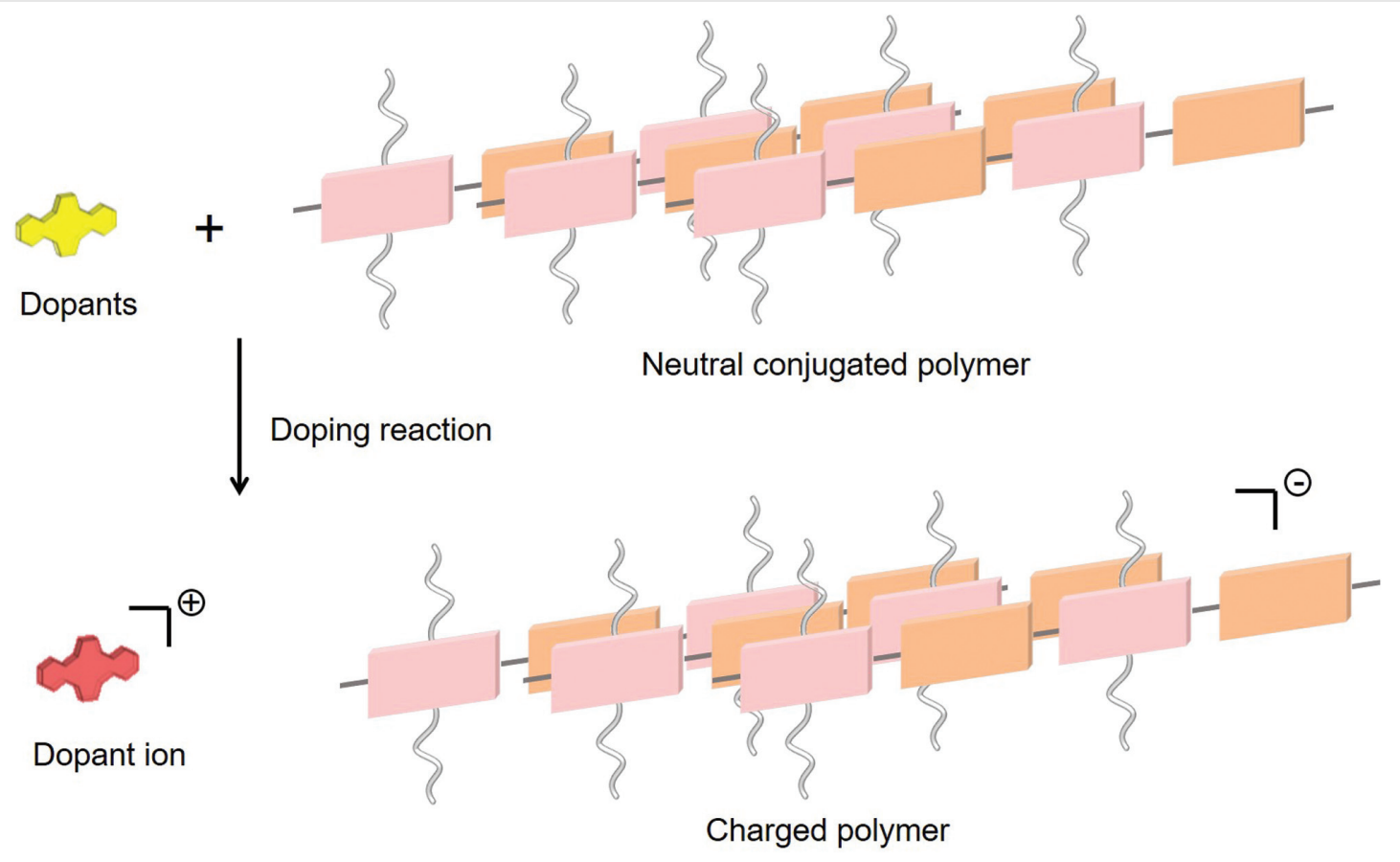

b)

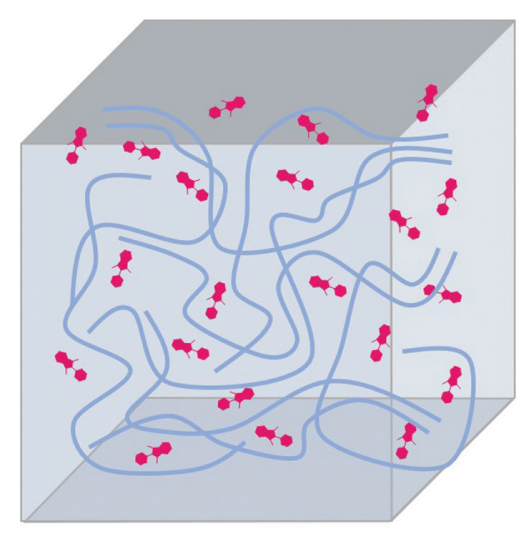

Polymer and dopants in solution

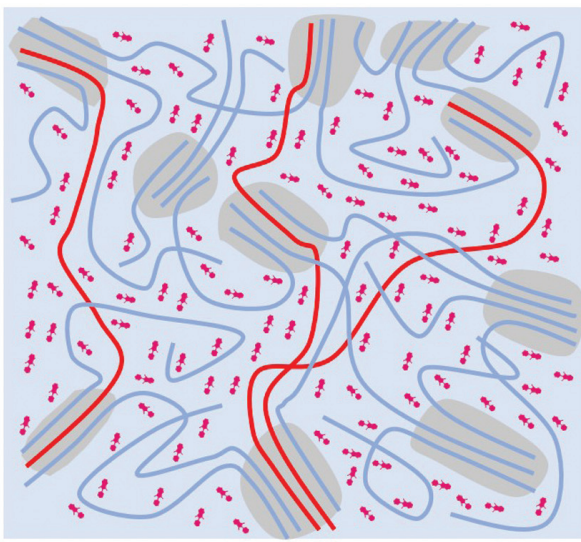

The microstructure of the film

Figure 1 a) Schematic diagram of the doping process between thermoelectrical conjugated polymers and dopants. b) Schematic diagram of the distribution of dopants and polymer in the solution and the microstructure of the corresponding film.

The microstructure relates not only to the structure and properties of polymers and dopants, but also to the doping and casting method from solution to the solid state. ${ }^{3 \mathrm{f}, 12}$ Moreover, the complex aggregation behavior of a polymer in solution and its relationship with the solid-state microstructure are still unclear. ${ }^{13} \mathrm{~A}$ high conductivity is critical to achieve a high power output for thermoelectric devices, and the microstructure effect on Seebeck coefficient is still unclear. In this review, we explain the change of the microstructure when introducing dopants, and summarize the strategies to tune the film morphology, further fabricating efficient devices with higher conductivity and thermoelectrical performance (Figure 1).

\section{Effects on Film Microstructures When Introducing Dopants}

Unlike the nearly perfect crystals of inorganic semiconductors, the intrinsic polymers tend to form smaller crystalline domains with a large population of defects in the solid state. The typical microstructures of a polymer film 
a)

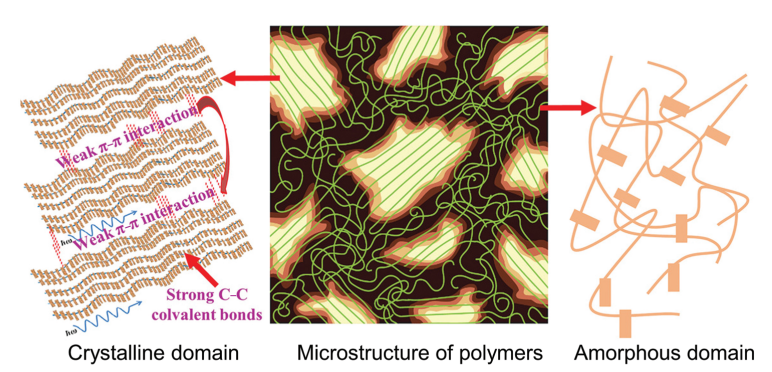

b)

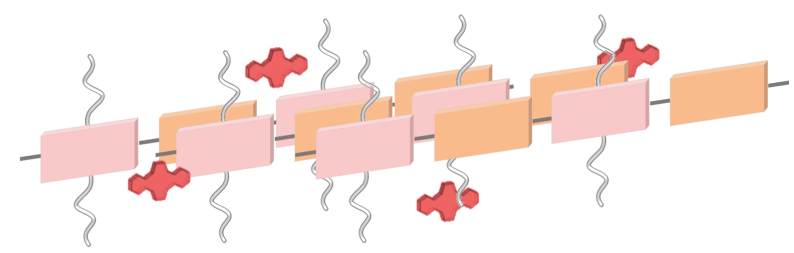

Figure 2 a) Schematic diagram of the microstructure of conjugated polymers. Adapted with permission from Ref. 14. Copyright 2019 Wiley-VCH Verlag GmbH \& Co. b) Schematic diagram of the distribution in the polymer backbone.

would be nanoscale crystalline domains bounded by highly disordered amorphous regions bridging neighboring ordered domains (Figure 2) ${ }^{14}$ Crystalline domains within conductive polymers possess ordered $\pi-\pi$ stacking of rigid conjugated chains, leading to the relatively unimpeded transport of electrons, while the amorphous domains exhibit localized electron transport, resulting in the significantly decreased mobility from amorphous chain stacking. ${ }^{15}$ Therefore, conductive polymers can be structurally considered as highly conductive domains surrounded by poorly conductive amorphous regions, while the ordered domains in polymer films are small in many cases. Because the charge carrier must traverse many domains during transport, the connections in the amorphous area are of vital importance. ${ }^{16}$

For thermoelectrics, a commonly used method to optimize the electrical performance of polymers is the introduction of molecular dopants, which can increase additional charge carriers by reducing, oxidizing, or transferring hydride to the semiconductors. In the doping process of inorganic semiconductors, impurity atoms are controllably introduced, which can dramatically increase the conductivity at ultralow doping ratios. Dopant atoms within the highly pure material are covalently bonded to the surrounding matrix homogeneously on the atom-scale. Different from inorganic semiconductor materials whose structures are homogeneous and crystalline, the doped polymers consist of spatially heterogeneous dopants which are coulombically bound to the polymer matrix. The addition or removal of electrons from the $\pi$-system of organic molecules causes intramolecular geometric distortions. The main optical absorption of the undoped polymers undergoes a substantial blue-shift after doping, owing to the formation of polaronic levels. There will appear a new absorption peak in the long-wavelength region at the same time, which demonstrates the doping process. $^{17}$ Dopants and polymers form charge transfer complexes in solution, and most dopants exist in a charged state. After the mixture solutions spin or drop-cast on the substrate to form the films, the position where dopants incorporate on the polymer backbone or side chain, ${ }^{18}$ the dopant distribution in the crystalline or the amorphous region, ${ }^{8 c, 12 \mathrm{e}}$ the dopant aggregation in the polymer matrix or uniform distribution, ${ }^{19}$ the interaction between polymer and dopant ions, and the miscibility all have great effect on the film microstructure and the electrical performance. ${ }^{20}$

When introduced small amounts of dopants, the generated charge carriers will fill the trap in the film first, resulting in enhanced mobility and carrier concentration, thus the increased conductivity. The small amounts of dopants have little effect on the interchain transport. When increasing the doping ratio, some dopants may distribute into the crystalline domain, resulting in larger $\pi-\pi$ stacking distances with decreased mobility and increased conductivity. While some dopants can exist in the amorphous region, the mobility has little influence. ${ }^{9 a, 21}$ A further increase in the doping ratio can result in phase separation between the polymer and dopants due to molecular aggregation and Coulombic interaction, hindering further loading of dopants and thus breaking the conducting network. Meanwhile, due to the weak interaction between the dopants and polymer, the dopants can diffuse in the film. Therefore, the film is unstable and has problems in long-time performance and operational stability. ${ }^{22}$ The complicated interactions and flexible combinations give the space to regulate the distribution of dopants in the polymer matrix. Investigation on the structure-property relationship to understand how dopants affect the microstructure in the doped state is an important direction of future research.

\section{Characterization of Doped Film Microstructures}

The microstructure is noteworthy because the local packing of neighboring molecules determines the electronic structure of the polymer and the connections of domains are crucial for the paths taken by charge carriers through the film. Due to the semi-crystallinity of the polymer film, the distribution and binding site of the induced dopants within the polymer film not only affect the crystalline region but also hinder the conducting network due to segregation. There are multiple-scale structures in polymer films, which include the molecular-scale packing such as $\pi-\pi$ stacking, the nanoscale order, the crystallinity and grain 
size/distribution, and the phase segregation. ${ }^{10}$ To clearly see the detailed information of the solid film, a series of characterization methods have been applied in the field of conductive polymers. Here, we briefly describe the important details of measurement techniques that we often used in polymer films.

\section{Atomic Force Microscopy}

Atomic force microscopy (AFM) is a method that uses a sharp tip to scan across the surface of a film to obtain a highresolution topographical map (Figure 3a). ${ }^{23}$ The AFM image is a convolution of the shape of the tip and the sample. What we should take care of is that the tip should always be sharper than the sample, or the image merely reflects the image of the tip. Because organic films are soft and sticky, the tip can always be contaminated and the most frequent artifacts may arise. ${ }^{24}$ AFM images reflect the surface morphology and can only provide the roughness information of a film surface. Sometimes it can provide the domain size and phase segregation of doped films. However, it is not possible to use the AFM images to determine the extent of crystallinity. X-ray or electron diffraction should be carried out to compare crystallinity of the films. Examples of AFM images are shown in Figure 3a. The intrinsic polymer film is relatively smooth; the dopant solution is sequentially casted. It can be observed that the doped film has aggregates on the surface and generates phase separation. There are some developments of combined technologies based on AFM. For example, AFM-based infrared spectroscopy (AFMIR) is a hybrid technique that combines AFM and infrared spectroscopy, which can provide chemical analysis and compositional mapping with spatial resolution. ${ }^{25}$ AFM-IR can distinguish the different components with dopants, polymers, or polymer-dopant complex of surface phase segregation. $^{26}$

Conductive AFM (c-AFM) is another method developed from AFM, which measures the variations in current and topography with good spatial resolution. ${ }^{27}$ It can be used to measure charge transport through samples with mixed conducting and poorly conducting domains, such as doped polymer films. Yang et al. performed the c-AFM to compare the distribution of conductivity of doped PDPH and PDPF. ${ }^{18 \mathrm{~b}}$ The PDPH film showed heavily local doping as the high conductivity islands were separated from the major lowconductivity regions. While PDPF exhibited a uniform conducting map, indicating the better miscibility between polymer PDPF and dopants.

Kelvin probe force microscopy (KPFM) is a method for performing local potentiometry at a film surface. ${ }^{28} \mathrm{KPFM}$ reflects the capacitive interaction between a metal (Pt/Ir)coated probe and the sample. Due to different distribution of surface species, the work function difference, manifested a)

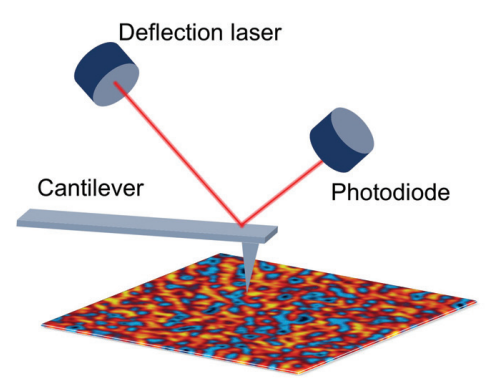

b)

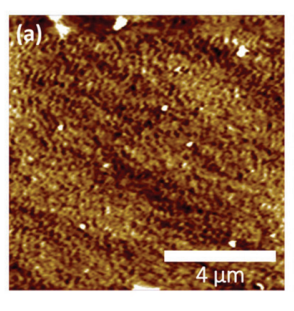

AFM

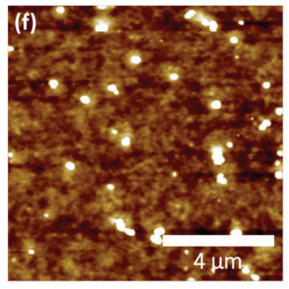

c)

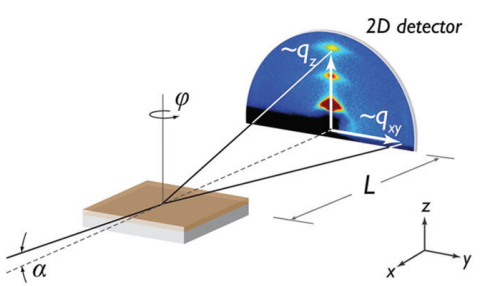

d)

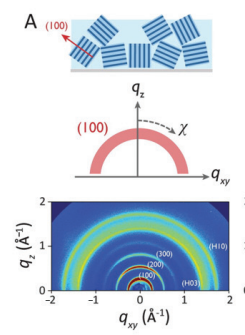

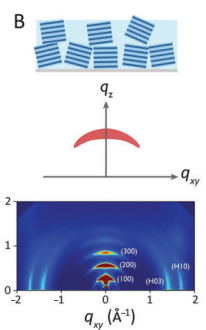

GIWAXS

Figure 3 a) Schematic picture of AFM. b) The AFM images of intrinsic P(BTP-DPP) and 0.92 monomeric dopants per repeat unit of the polymer. Adapted with permission from Ref. 36. Copyright 2017 American Chemical Society. c, d) Schematic picture of GIWAXS. Adapted with permission from Ref. 10. Copyright 2012 American Chemical Society. e) Schematic picture of RsoXS. f) RsoXS profiles in log scale for doped FBDPPV. Adapted with permission from Ref. 32. Copyright 2016 American Chemical Society. 
as the surface potential contrast (SPC), which can be recognized by the interaction between the probe and the sample, can reflect the distribution of dopants. ${ }^{29}$ Since chemical doping of a conjugated polymer by iodine vapor alters the polymer's work function, KPFM can track and map the changes on the film surface when doping. Recently, Boyle et al. mapped the SPC of P3HT and PDPP4T films doped at $25^{\circ} \mathrm{C}$ and $75^{\circ} \mathrm{C}$. ${ }^{12 a}$ They observed that P3HT films doped at $25{ }^{\circ} \mathrm{C}$ displayed an obviously wide distribution of SPC and regions of densely doped states, indicating that the distribution of iodine-doped states is heterogeneous, while the intrinsic P3HT has a narrow distribution of SPCs. Compared to P3HT, PDPP4T is doped with a more homogeneous distribution of iodine-doped states, and the homogeneity of iodine-doped states increases with increasing the doping temperature.

\section{Grazing-Incidence Wide-Angle X-Ray Scattering}

Grazing-incidence wide-angle X-ray scattering (GIWAXS) is a method for characterizing the details of crystallographic structures (Figure $3 \mathrm{~b}$ ). ${ }^{10,30}$ GIWAXS should be performed at a synchrotron for polymeric semiconductors, which is optimal due to both high flux and collimation of the photons.

It is a commonly used tool to qualitatively calculate the crystallinity of the polymer films, and to determine the lattice spacing of observed peaks. The 2D plots can intuitively give the information of the number of the crystalline peaks, as well as the corresponding intensity, the crystallite orientation, and the qualitative comparison of crystallinity. The $1 \mathrm{D}$ plots can be used to compare the change of the lamellar distance or the $\pi-\pi$ stacking distance, and sometimes to quote the corresponding grain size or coherence length. To determine the relative changes in crystallinity, a pole figure can be obtained, which can describe the orientational distribution of the diffracted intensity of a chosen diffraction peak as a function of possible crystallite orientations. ${ }^{31}$ For example, a FBDPPV film shows weak diffraction peaks in 2D GIWAXS patterns (Figure 4). ${ }^{32}$ When introducing dopants, the (h00) scattering peak and the out-of-plane scattering (010) peak become weaker at the dopant concentration of $1 \mathrm{wt} \%$. At 3-7 wt\%, the (010) and (h00) scattering peaks are enhanced. Further addition of dopants (15-50 wt\%) leads to an enhanced out-of-plane order, a decreased in-plane order, and a (010) $\pi-\pi$ stacking order, which means that a high dopant ratio can destroy the polymer's molecular packing. The coherence length of (010) peaks can be used to analyze the molecular packing of FBDPPV. The coherence length decreases at the very beginning and increases to the maximum when 5-7 wt\% dopant is introduced. This suggests that a small amount of dopant can induce the
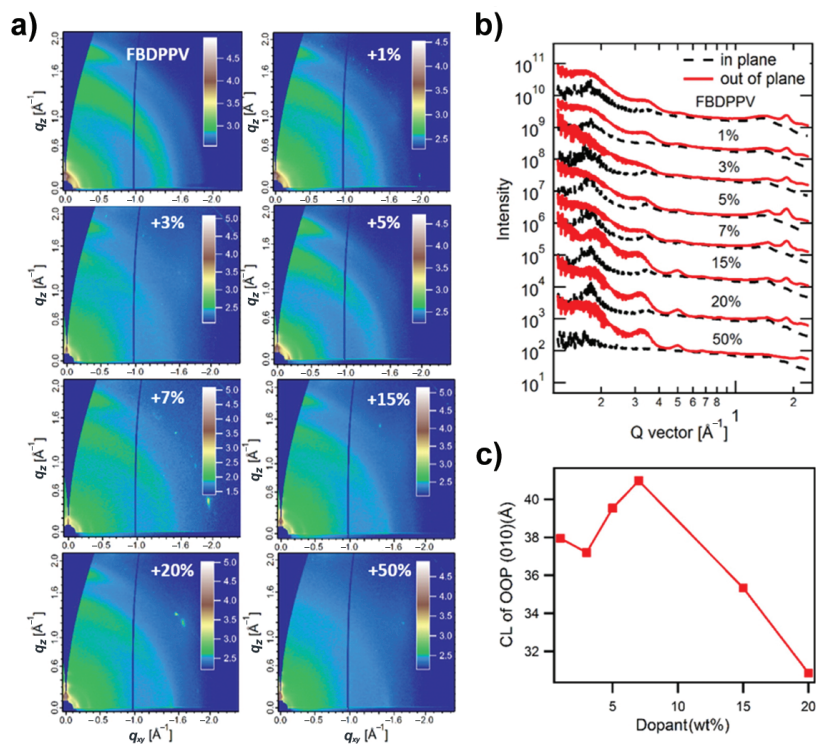

Figure 4 a) 2D GIWAXS images of FBDPPV films with different doping concentrations. b) In-plane and out-of-plane plots extracted from 2D GIWAXS images with different amounts of dopant N-DMBI. c) Out-ofplane (010) coherence length (CL). Adapted with permission from Ref. 32. Copyright 2016 American Chemical Society.

face-on molecular packing and meanwhile the excess can destroy the film microstructure.

\section{Resonant Soft X-Ray Scattering}

Resonant soft X-ray scattering (RsoXS) is a technique for revealing the length scale of a molecular orientation in both crystalline and amorphous domains over the range of $10-1000 \mathrm{~nm}$ (Figure 3c). ${ }^{33}$ RSoXS uses soft X-ray absorption to increase the scattering length and to control the scattering contrast. In $\pi$-conjugated molecules, the transition dipole moment for the excitation of a core electron to unoccupied p-orbitals is orthogonal to the $\pi$-conjugated plane of the molecule. The scattering contrast can be generated by variations in the molecular orientation by using a linearly polarized soft X-ray and tuning the photon energy to the $\mathrm{C} 1 \mathrm{~s}$ to $\pi^{*}$ resonance. Using RSoXS measurements, we can qualify the backbone alignment through the orientational correlation length (OCL). The OCL is proven to have an empirical exponential relationship with field-effect mobility values. Patel et al. used the trend of OCL to confirm the significant role of backbone alignment in controlling conductivity. ${ }^{12 \mathrm{e}}$ The difference of OCL between an as-cast neat film $(\sim 70 \mathrm{~nm})$ and the PBTTT:F4TCNQ annealed film $(\sim 44 \mathrm{~nm})$ indicates that doping in solution slightly reduces the OCL relative to a neat film before annealing. The 
annealed solution-doped film shows an OCL of $44 \mathrm{~nm}$, which means that annealing a heavily doped film has no influence on improving the backbone alignment. It can also explain the similar conductivity values of the cast and the annealed solution-doped films. Ma et al. employed RSoXS to explore the phase separation between dopant-conjugated polymers. $^{32}$ The scattering is caused by the surface roughness at low $q\left(q<0.03 \mathrm{~nm}^{-1}\right)$ and the phase separation can be shown at high $q$. They observed that the all N-DMBI-doped FBDPPV films showed similar double peaks at $q \approx 0.17$ and $0.44 \mathrm{~nm}^{-1}$, which corresponded to the small phase separation. The small and similar phase separation within a large-scale doping concentration indicates the good miscibility of the polymer and dopants and suggests that excess dopants do not aggregate in the bulk but form big aggregates on the surface of the film.

\section{Strategies to Improve the Microstructure and Thus the Conductivity}

The microstructure of a doped film can be affected by many factors, such as the nature of the polymer, ${ }^{34}$ the degree of crystallinity, ${ }^{8 b}$ and the miscibility of the dopant with crystalline and amorphous phases of polymers. ${ }^{8 f}$ The balance of the charge carriers induced by dopants and the changes of the morphology result in the final conductivity. Some strategies have been reported to tune the morphology and get higher conductivity, such as optimizing the structure of polymers and dopants (Figure 5), and adopting a suitable process.

\section{Optimizing the Structure of Polymers}

In the doping process, phase segregation often happens between polymers and dopants, which will destroy the conductive network and decrease the conductivity. Hence polymer structures are redesigned to optimize the doping efficiency. The most famous and widely used n-type polymer P(NDI2ODT2), also called N2200, showed the conductivity of $5 \times 10^{-3} \mathrm{~S} \mathrm{~cm}^{-1}$ when doped with $\mathrm{N}$ DMBI. $^{35}$ To optimize the molecular structure, Liu et al. changed the traditional alkyl side chains to polar triethylene glycol-based side chains and synthesized the polymer TEGN2200. TEG-N2200 achieved a high electrical conductivity a)

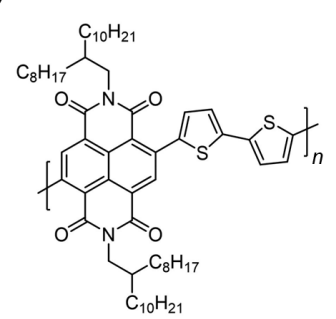

P(NDIODT2) (N2200)

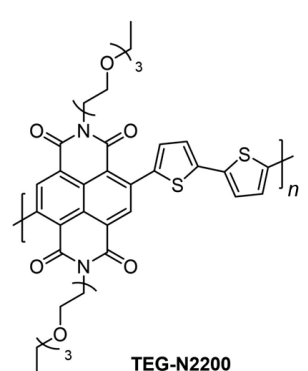

TEG-N2200

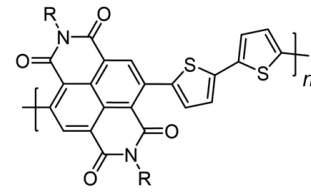

饮

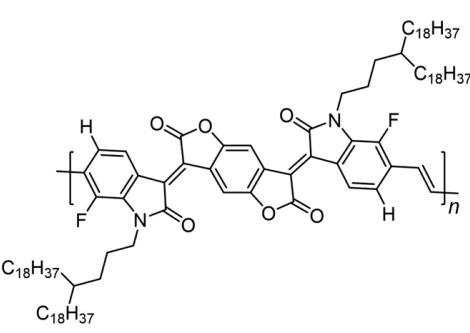

FBDPPV
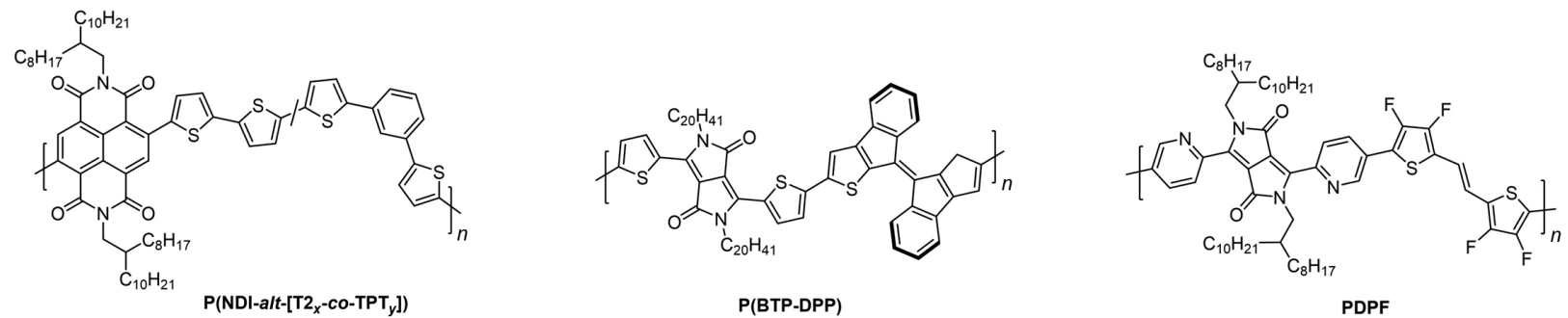

b)
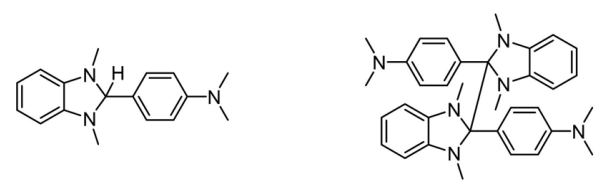

N-DMBI

(N-DMBI) 2
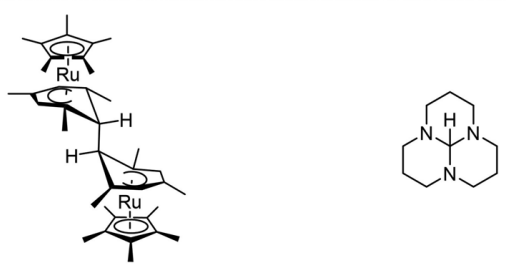

(RuCp*mes)

TAM 
of $0.17 \mathrm{~S} \mathrm{~cm}^{-1}$, showing 200 -fold enhancement compared to the electrical conductivity of N2200 when doped with NDMBI. ${ }^{18 a}$ Coarse-grained molecular dynamics (MD) simulations suggested that the dopants were more likely to disperse into the polymer matrix, rather than forming clusters in the alkyl chains. The TEG-N2200 showed a reduced phase separation observed from the AFM morphology images when introducing excess dopants compared to N2200. The excellent contact and miscibility between polymers and dopants in the NDI-based system with polar side chains improve the doping efficiency and boost the conductivity. Similar strategies have also been applied in p(gNDI-gT2), which contains polar oligoethylene glycol-containing side chains on both the NDI acceptor and the bithiophene donor, achieving a conductivity of $0.3 \mathrm{~S} \mathrm{~cm}^{-1}$. ${ }^{34 a}$ AFM showed little surface roughness changes of p(gNDI-gT2) with a high doping fraction of 20-30 mol\% $\mathrm{N}-\mathrm{DMBI}$, while N2200 with a low dopant concentration of $9 \mathrm{~mol} \%$ showed clearly visible aggregates on the film surface. This suggests that p(gNDI-gT2) has better miscibility with dopants and the nanostructure of the polymer film is largely maintained even with a high doping concentration. The above reports demonstrate that the polar side chains of polymers can improve the miscibility of polymers and dopants, show less phase separation with a high dopant fraction, and keep better conductive networks.

Yang et al. weakened the interchain interaction by decreasing the electron-donating ability of the donor, synthesizing the polymer PDPF, which has better miscibility with dopants N-DMBI. ${ }^{18 \mathrm{~b}}$ PDPF, which has four fluorine atoms on the donor moiety, showed the conductivity of $1.3 \mathrm{~S} \mathrm{~cm}^{-1}$, more than 1000 times higher than that of PDPH. In the doped state, PDPH films showed larger film roughness and new aggregates when the doping concentration was over 5\%. However, PDPF displays good miscibility with $\mathrm{N}$ DMBI with no obvious phase separation. The introduction of fluorine atoms results in different intermolecular packing. From GIWAXS, PDPH presents a nearly complete edge-on orientation, while PDPF has both edge-on and face-on orientations. The multiple packing in PDPF can develop more transmission paths and tolerate more dopants.

Another representative process to improve the miscibility is to introduce a twisted building block in the polymer backbone. Nonplanar n-doped ambipolar polymer P(BTPDPP), processed by sequential casting with (RuCp*mes) showed a maximum conductivity of $0.45 \mathrm{~S} \mathrm{~cm}^{-1}$. $^{36}$ The steric space created by the nonplanar unit in the backbone and glassy ordering allows for efficient incorporation of the dopant. To overcome the low conductivity caused by the poor miscibility of the dopant with polymer, Shin et al. added controllable amounts of the kinked monomer 1,3-bis (2-thienyl)benzene (TPT) into the straight backbone of PNDIT2, getting a new polymer, P(NDI-alt-[T2-co-TPT]). ${ }^{37}$ Differential scanning calorimetry measurements were employed to investigate the miscibility of P(NDI-alt-[T2co-TPT]) with n-dopant N-DPBI. The degree of crystallinity of dopant N-DPBI can be demonstrated by comparing the melting enthalpies $\Delta H_{\mathrm{m}}$ of the dopant N-DPBI in the doped films, thus deducing the miscibility of dopants and the polymer. The polymer P(NDI-alt-[T2-co-TPT]) with a TPT content over $30 \mathrm{~mol} \%$ showed lower $\Delta H_{\mathrm{m}}$, which suggests the better miscibility when the TPT content is up to $30 \mathrm{~mol} \%$. However, a better miscibility does not result in a better conductivity due to the decreased mobility, although the doping efficiency was substantially improved. $\mathrm{P}\left(\mathrm{NDI}-\right.$ alt-[T2 $\left.\left.98_{-}-\mathrm{Co}-\mathrm{TPT}_{2}\right]\right)$ with $2 \mathrm{~mol} \%$ TPT showed an enhanced miscibility with N-DPBI and a decreased mobility compared to PNDIT2 without TPT, resulting in a decreased conductivity. $\mathrm{P}\left(\mathrm{NDI}-\right.$ alt-[ $\left.\left.\mathrm{T}_{70}-\mathrm{Co}_{-} \mathrm{TPT}_{30}\right]\right)$ has a higher charge carrier concentration but a larger decreased mobility due to the broken conjugated backbone, showing lower conductivity than $\mathrm{P}\left(\mathrm{NDI}-\right.$ alt-[T2 $\left.\left.98-\mathrm{co}-\mathrm{TPT}_{2}\right]\right)$. The above two polymers show the importance of balancing the electronic properties of the polymer structure and the miscibility with dopants. Therefore, the choice of organic semiconductors for high conductivity systems should not just consider the miscibility of polymers and dopants or high mobility in field-effect transistors.

The design of polymer structure is mainly focused on two aspects. One is to increase the interchain interaction to facilitate the charge transport. For example, using molecular aggregation to promote the tight packing mode with multiple $\pi-\pi$ bonding, ${ }^{38}$ or the introduction of heavy atoms to enable stronger intermolecular interaction. ${ }^{39}$ The other one is to enhance the miscibility between polymers and dopants, such as the introduction of polar ethylene glycol side chains, ${ }^{18 a, 34 a}$ using "kinked" donor moieties, ${ }^{34 d}$ and introduction of twisted building blocks. ${ }^{36}$ However, the two design strategies have opposite effects on the conductivity. We should find a balance between mobility and doping efficiency in the doped system, which is a big challenge for the polymer design. Recently, some studies have developed electron-deficient D-A conjugated polymers and successfully balanced the trade-off between the increased charge carriers and the mobility. ${ }^{18 \mathrm{~b}, 21}$ The electron-deficient donor and accepter groups may have better miscibility with dopants.

\section{Optimizing the Structure of Dopants}

The dopant molecules, as a component in the doped polymer film, are noncovalently bonded to the polymer, and heterogeneously dispersed in doped polymer films. The efficiency of the doping reaction and the property of dopants may have an effect on the final performance of the films. ${ }^{40}$ Un et al. studied the relationship between the shape of dopant counterion and the final thermoelectric 


$\begin{array}{lll}\text { Organic Materials } & \text { M. Xiong et al. } & \text { THIEME } \\ \text { OPEN } \\ \text { ACCESS }\end{array}$
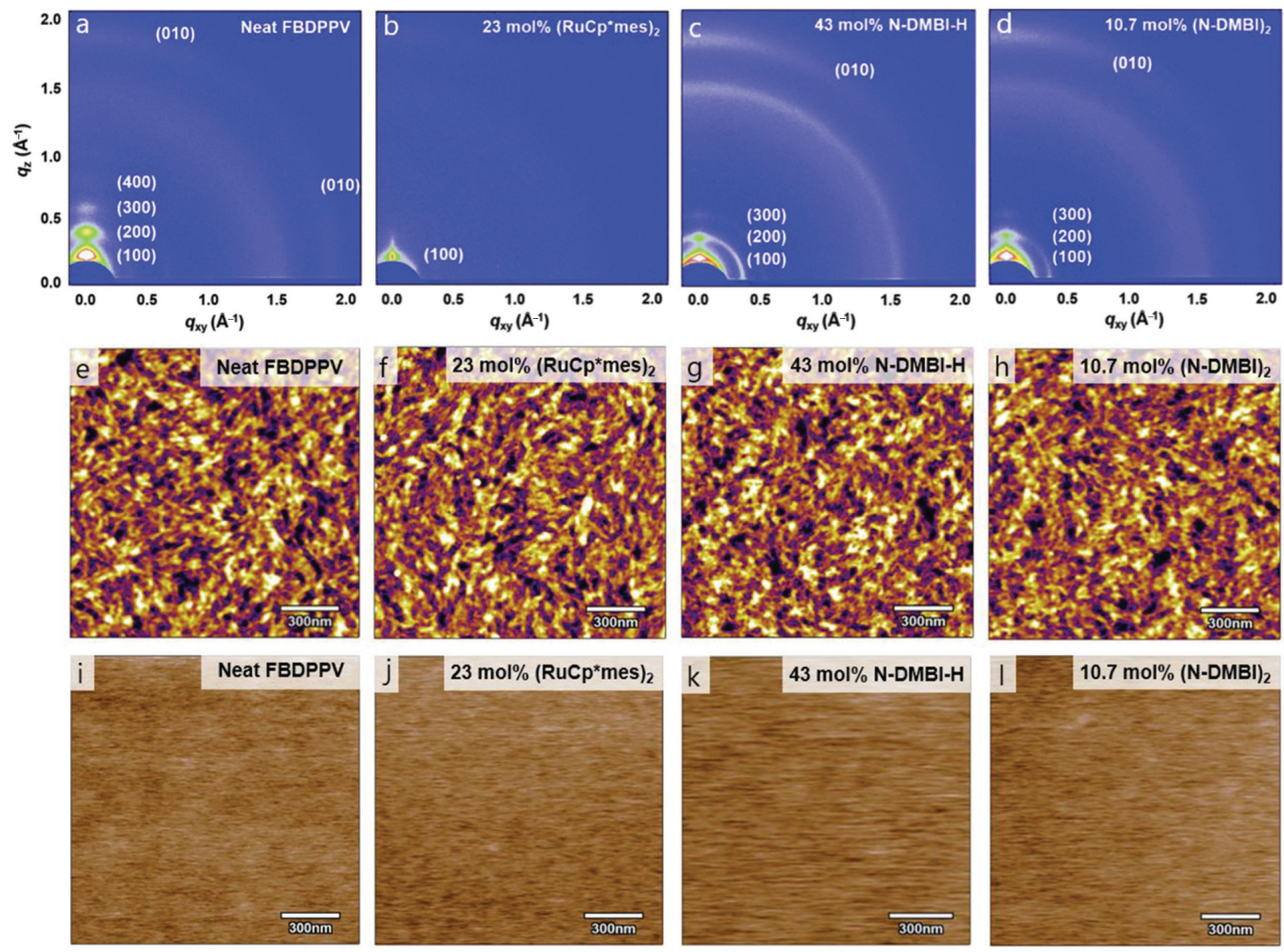

Figure 6 Microstructure and morphology of intrinsic polymer films and (RuCp*mes) $2, N$-DMBI, and (N-DMBI) 2 -doped films with different doping concentrations. a-d) GIWAXS images. e-h) Surface morphology in AFM maps. i-l) Potential mapping by SKPM. Adapted with permission from Ref. 41. Copyright 2016 Wiley-VCH Verlag GmbH \& Co.

properties (Figure 6). ${ }^{41}$ They selected $(\mathrm{N}-\mathrm{DMBI})_{2}$, (RuCp*mes) $)_{2}$, and the widely used N-DMBI to dope FBDPPV. $(\mathrm{N}-\mathrm{DMBI})_{2}$ systems were designed to decouple the effect of the different doping mechanisms from the counterion size, which has the same doping mechanism as (RuCp*mes) $)_{2}$ and generates the same cation moiety $\mathrm{N}-\mathrm{DMBI}^{+}$with $\mathrm{N}-\mathrm{DMBI}$ after doping. N-DMBI usually involved in the hydrogentransfer reactions and the counterion had a more planar structure with a $51.9^{\circ}$ twist between planes formed by the imidazolium and arene portions of the cation. (RuCp*mes) $)_{2}$ contributes the electron during the doping process and forms two monomeric cations, (RuCp*mes) ${ }^{+}$, which had a bulky cylindrical shape. In GIWAXS plots, only (100) can be observed in the (RuCp*mes) $)^{+}$system with no $\pi-\pi$ stacking scattering, while the two $\mathrm{N}-\mathrm{DMBI}^{+}$systems exhibit multiple order scattering features and obvious $\pi-\pi$ scattering. Due to the relatively small and planar structure of the counterion, the N-DMBI and (N-DMBI) 2 systems can be tolerated easily in the lamellar alkyl-chain region, according to the almost unchanged $\pi-\pi$ stacking distance. The bulky (RuCp*mes) ${ }^{+}$ enlarged the lamellar distance and destroyed the $\pi-\pi$ stacking. The following electrical characteristics show that the highest conductivity for FBDPPV doped with (RuCp*mes) $)^{2}$ is $1.6 \mathrm{~S} \mathrm{~cm}^{-1}$ at $23 \mathrm{~mol}$ \% doping concentration. While the maximal conductivity of FBDPPV doped by NDMBI and $(\mathrm{N}-\mathrm{DMBI})_{2}$ reaches $8 \mathrm{~S} \mathrm{~cm}^{-1}$ at $42 \mathrm{~mol} \%$ and $10.7 \mathrm{~mol} \%$ dopant concentrations, respectively. (N-DMBI $)_{2}$ with a better doping efficiency and a more planar structure of counterion leads to a more ordered polymer film microstructure and a better electrical performance. The result suggests that a more planar dopant counterion and an efficient electron-transfer reaction should be considered to obtain an optimized morphology.

To solve the miscibility of polymers/dopants and design effective dopants, a recent research reported a computerassisted screening approach to design a trisaminomethanetype dopant by density functional theory calculations and MD simulations, obtaining the optimal dopant TAM 
a)

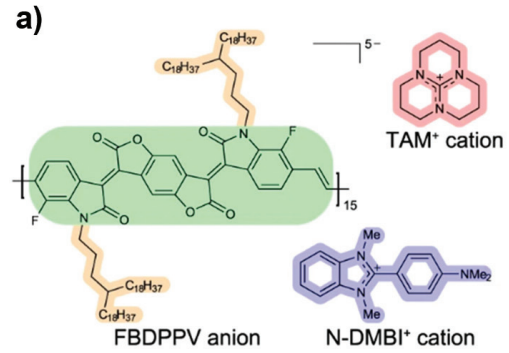

c)

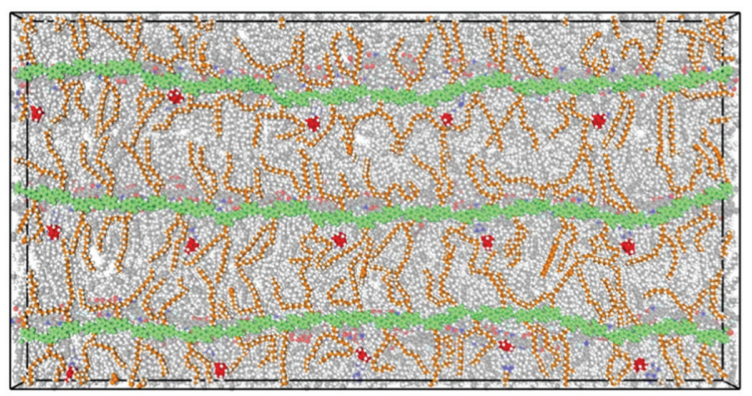

e)

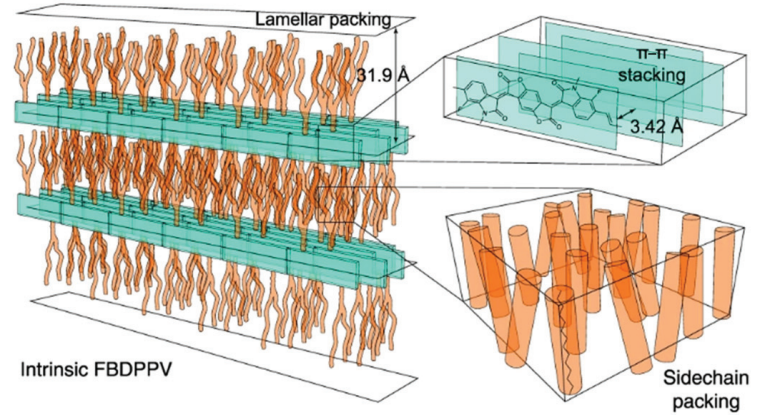

b)

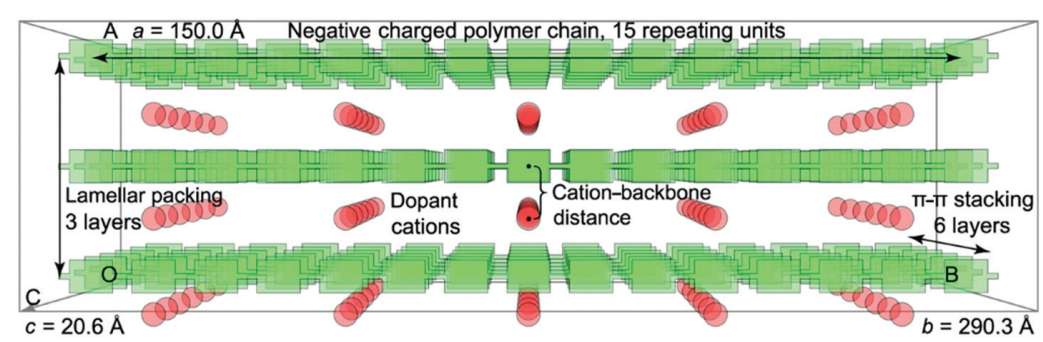

d)

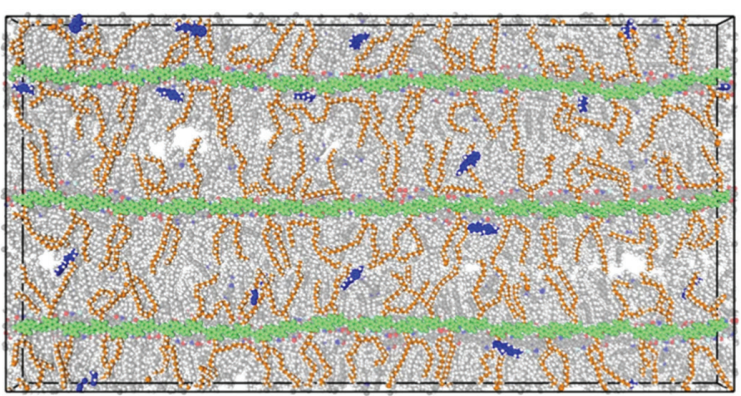

f)

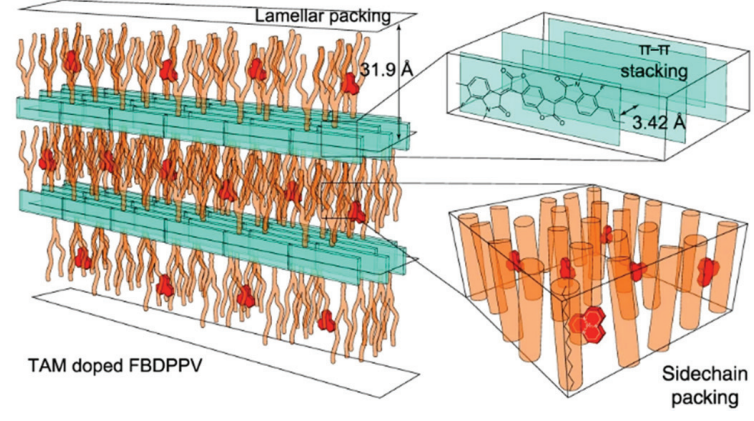

Figure 7 a) Chemical structure of FBDPPV anions, $\mathrm{TAM}^{+}$, and N-DMBI ${ }^{+}$cations. b) Schematic diagram of initial supercell for molecular dynamics. c, d) Equilibrium configurations of FBDPPV and TAM, N-DMBI. e, f) Schematic diagram of the molecular packing models in the intrinsic and TAM-doped FBDPPV. Adapted with permission from Ref. 42. Copyright 2020 Springer Nature.

(Figure 7). ${ }^{42}$ Compared to the state-of-the-art n-dopant NDMBI, TAM showed better solubility and chemical stability. MD simulations were used to study the different behaviors of TAM and N-DMBI cations with polymer FBDPPV anions. Most of $\mathrm{TAM}^{+}$cations stayed within the alkyl side chain due to the similar polarizability, but stayed away from the polymer-conjugated backbones. In contrast, $\mathrm{NDMBI}^{+}$was crowded out by the alkyl chains and had stronger interactions with polymer backbones. GIWAXS data showed that after TAM doping, the lamellar packing distance and $\pi-$ $\pi$ stacking distance of FBDPPV and N2200 remained almost the same, demonstrating that TAM has excellent miscibility with the conjugated polymers and "dopant-at-side-chain" microstructures. TAM-doped FBDPPV thick films realized high electron conductivity and PF among n-type thermoelectric polymers. It should be emphasized that not only the doping efficiency but also the impact on the film microstructure should be considered when designing the dopants. $^{43}$

\section{Optimizing the Device Fabrication Methods}

The doping methods also have an important influence on the microstructure of a doped film. To facilitate the largescale processing of the devices, solution-processing methods of polymers and dopants are widely used.

For obtaining a conducting polymer film, a convenient method is to mix the polymer solution and dopant solution directly and co-deposit by spin coating, which has been used in most studies in the literature. Many highconductivity systems are processed using solution blending, ${ }^{44}$ such as PEDOT:PSS and the $\mathrm{n}$-doped polymer $\mathrm{P}$ (PzDPP-CT2). ${ }^{21}$ The method is very easy, controllable, low- 
a)

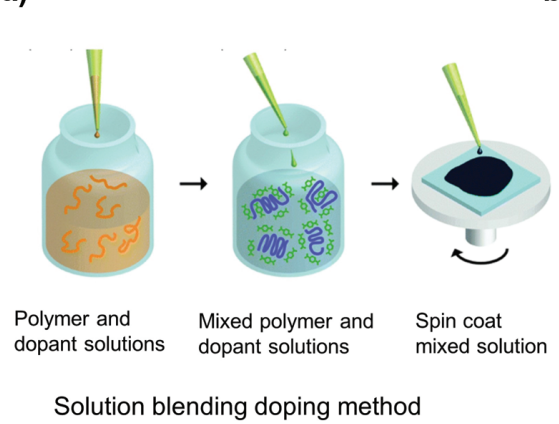

d)

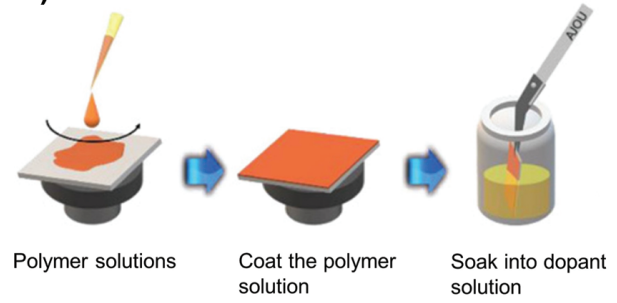

Solution soaking doping method b)

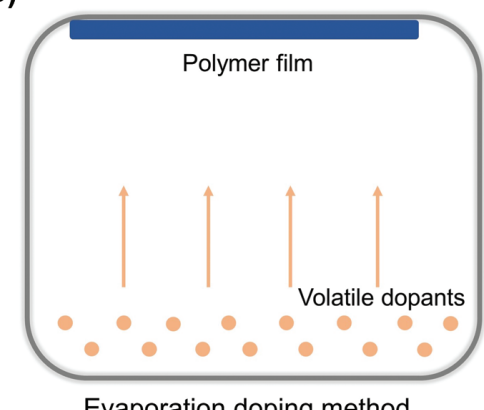

Evaporation doping method c)

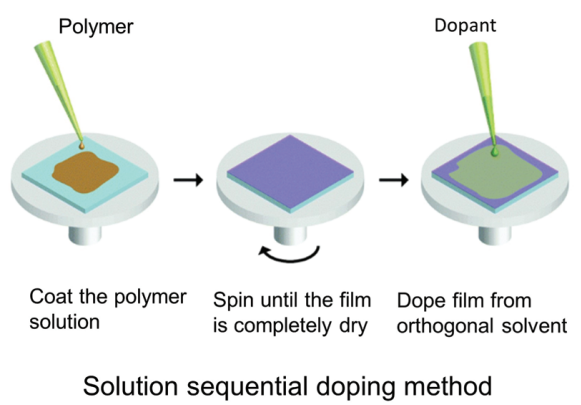

e)

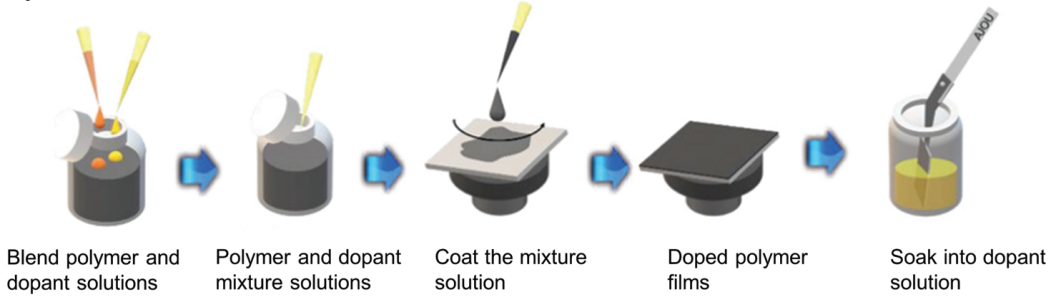

"Hybrid doping method" (Solution blending method + Solution soaking method)

Figure 8 a) Solution blending doping method. b) Evaporation doping method. c) Solution sequential doping method. d) Solution soaking doping method. e) Hybrid doping method, combined solution soaking doping and solution blending method. Diagrams a) and c) are adapted with permission from Ref. 8c. Copyright 2016 The Royal Society of Chemistry. Diagrams d) and e) are adapted with permission from Ref. 51. Copyright 2020 Wiley-VCH Verlag $\mathrm{GmbH} \&$ Co.

cost, and saves materials in the industry. However, the major disadvantages of the method are that (1) the polymers and dopants have different solubility in the same solvent; (2) excess dopants are easily introduced into the film, causing phase separation; (3) many polymers show reduced solubility when they are ionized in mixture by electron transfer or forming charge transfer complexes, which makes the charged species crush out of solution and affects the film microstructure. ${ }^{45}$ Jha et al. studied the doping efficiency of PBTTT doped by F4TCNQ using the solution-blending method and demonstrated that the strong Coulombic interactions of ions in the solution were retained to the processed films, which made the charge carrier localized, affording a poor doping efficiency (Figure 8a). ${ }^{46}$ The strong interaction between the dopant and polymer in the mixture makes a big difference between doped polymer films and intrinsic films. However, the solubility of some systems can also be increased after doping. Karpov et al. developed a strong pdopant CN6-CP, which was originally insoluble, and discovered that the doped complex of polymer PDPP(6DO) ${ }_{2}$ had good solubility. ${ }^{45 b}$ No signs of phase separation in AFM maps and no dopant crystal reflections in GIWAXS data at high doping concentrations demonstrated a stable complex and cocrystallization ${ }^{20 a}$ between the polymer and dopants.
Another solution-processing method is sequential deposition. In this method, the polymer solution is deposited on the substrate first, and then the dopant solution is deposited on the polymer film. The dopant deposited with an orthogonal solvent or evaporation will not dissolve the polymer film. Small dopants can penetrate into the film, which has little influence on the crystalline domains, retaining the film mobility (Figure 8b, c) ${ }^{8 \mathrm{~d}, 47}$ Fontana et al. compared two sequential doping methods: evaporation doping, in which the dopant was added via thermal sublimation, and solution doping, in which the dopant was spin-coated from a chosen solvent to swell the polymer film (Figure 9). ${ }^{2 \mathrm{~b}}$ The dopant F4TCNQ was used to dope P3HT polymer films with different thicknesses by the two doping processes. For the evaporation doping, the optimal evaporated dopants' thickness must reach $1 / 3$ of the underlying polymer films to achieve maximal conductivity of $\sim 5 \mathrm{~S} \mathrm{~cm}^{-1}$. The method was limited by the diffusion of dopants into the films, and can only dope the films up to $400 \mathrm{~nm}$. The appearance of a (400) lamellar peak and coherence lengths in GIWAXS plots showed the improved long-range crystallinity, which explained the higher conductivity compared to the solution sequential doping. For the solution sequential doping, fewer dopants were used, but it was not easy to find the optimal orthogonal 
a)
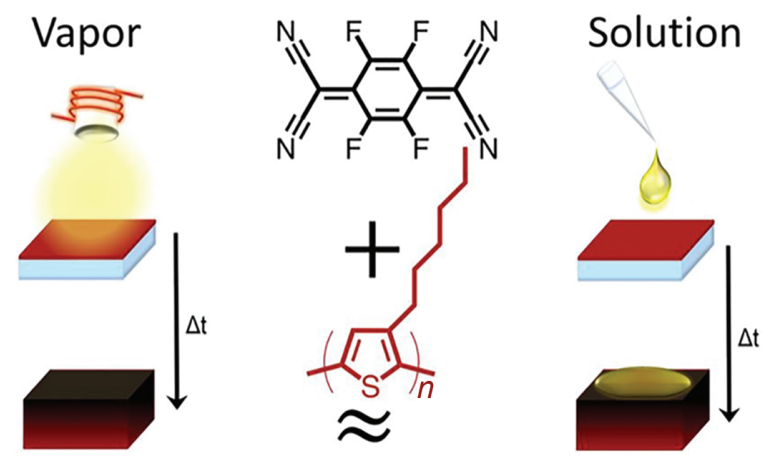

b)

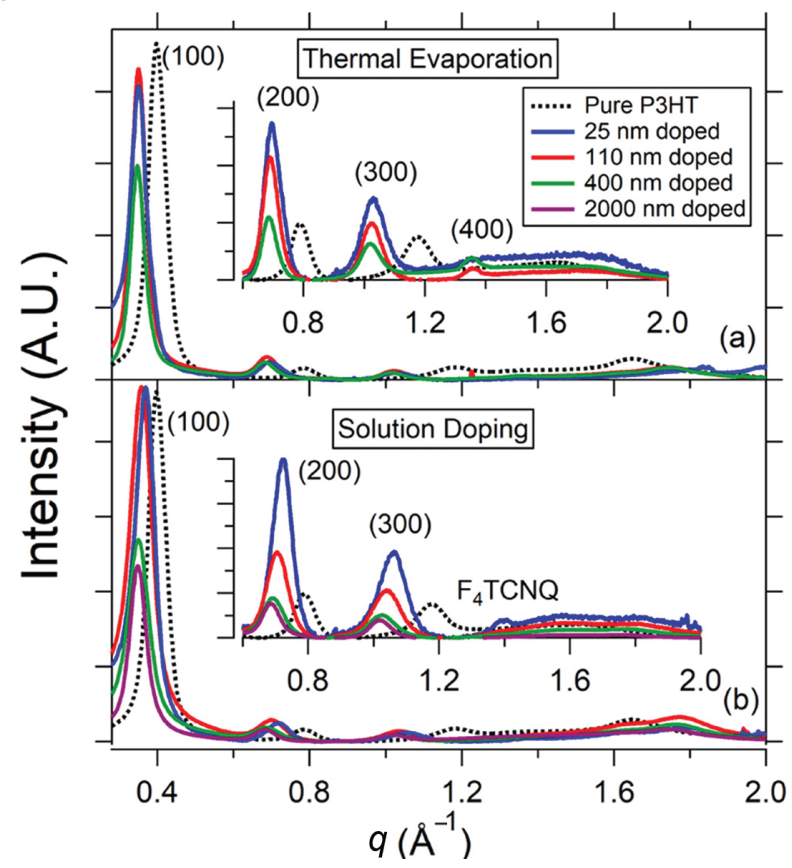

Figure 9 a) Schematic showing sequential doping of conjugated polymer films using evaporation doping and solution sequential doping. b) Out-of-plane plots from 2D GIWAXS diffraction maps of P3HT films doped with F4TCNQ via thermal evaporation and solution sequential process. Adapted with permission from Ref. 12b. Copyright 2019 American Chemical Society.

solvent to dissolve dopants and swell the polymer efficiently. This method can dope the polymer films as thick as $2 \mu \mathrm{m}$ and achieve a conductivity of $\sim 5 \mathrm{~S} \mathrm{~cm}^{-1}$. Both the sequential methods can keep the microstructure of the precast polymer films roughly intact and achieve a similar doping level in reasonable doping concentrations. If over-doped, the dopants would remain neutral in the amorphous region or on the top of the film, resulting in a decreased conductivity due to the increased film thickness. It is challenging for both techniques to add the dopants into thicker films and achieve effective doping. $^{3 \mathrm{~d}, 48}$

Jacobs et al. compared the different film microstructures formed in the solution-blending process and solution sequential doping process by investigating the F4TCNQ-doped P3HT system (Figure 10). ${ }^{8 \mathrm{c}}$ For the solution-mixed method, doping-induced aggregation and P3HT:F4TCNQ with reduced solubility in solution may cause disconnection of domains in films. The films show reduced mobility and increased trapped charge carriers. AFM images showed significantly rougher films, and a shift in $\pi-\pi$ stacking and lamellar stacking distance between intrinsic P3HT and films from P3HT:F4TCNQ mixed-solution was shown in XRD, which indicates that the small dopant molecules are intercalated into the P3HT crystallites. For the solution sequential doping process, the polymer film morphology can be preserved with lots of tie chains to connect the crystalline domains. The subsequent doping process can obtain a higher conductivity with high mobility. The choice of solvents used to dissolve the dopants was very critical for enhancing the performance of polymer films, which have different permeability to polymer films. ${ }^{49}$ They found that the doped films processed from $\mathrm{CH}_{3} \mathrm{CN}$ and chlorobenzene $(\mathrm{CB})$ as the dopant solvent exhibit different morphology. Doping from $\mathrm{CH}_{3} \mathrm{CN}$ leaves the dopant F4TCNQ in the amorphous domains, and polarons move to crystalline domains, thus allowing high conductivity. This can be proved by the same $\pi-\pi$ stacking distances between undoped P3HT and P3HT:F4TCNQ films. In contrast, when the good solvent $C B$ is used for the sequential doping, the crystallites are swollen by solvents according to the increased $\pi-\pi$ stacking distances in electron diffraction patterns. It can introduce more dopants and increase the doping level, however, reducing the conductivity and doping efficiency due to the destroyed crystalline domains and decreased mobility. This indicated that the incorporation of dopant anions into crystalline domains limited the transportation of charge carriers. For sequential doping, the main advantages are the convenient control of dopant distribution and the modulation of the film microstructures. Highly conductive polymer films can be realized through spatially separated dopant counterions out of the effective conductive pathway.

The sequential soaking doping method is also a sequential doping process, which gives the posttreatment to the polymer films by soaking in dopant solution with different concentrations and soaking time. ${ }^{50}$ Recently, a new doping method, "hybrid doping," which combines the solution blending method and sequential soaking process, was reported to maximize the doping efficiency of polymers without destroying the surface morphology. ${ }^{51}$ For the hybrid doping method, the mixture solution of 


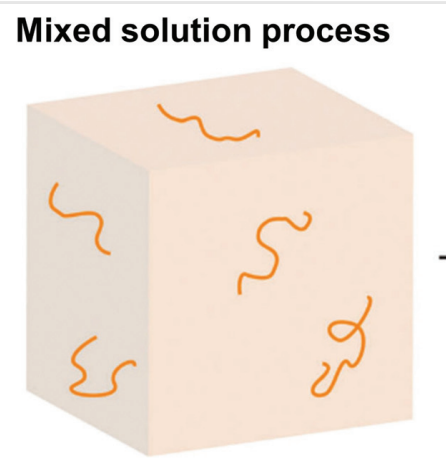

Solvated polymer (orange lines)

\section{Sequential doping process}

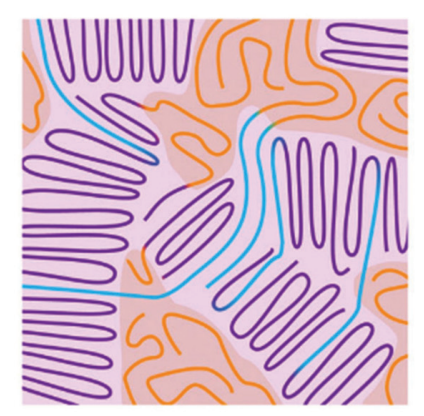

Initial undoped film with good morphology and lots of tie chains (blue lines)

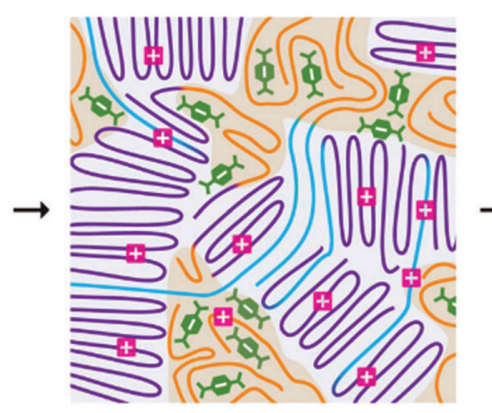

Sequential doping from $\mathrm{CH}_{3} \mathrm{CN}$ preserves morphology and phase-segregates polarons and F4TCNQ*-anions, allowing high conductivity

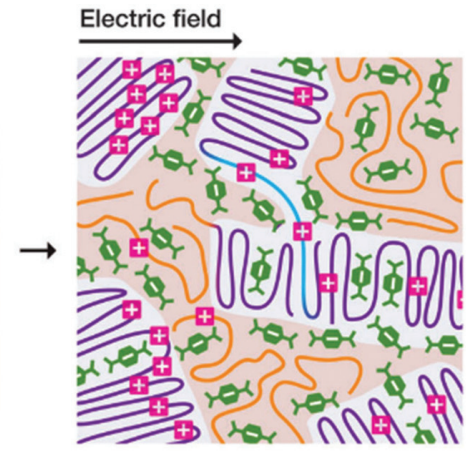

Resulting film contains few tie-chains (blue lines) connecting crystallites, lowering conductivity

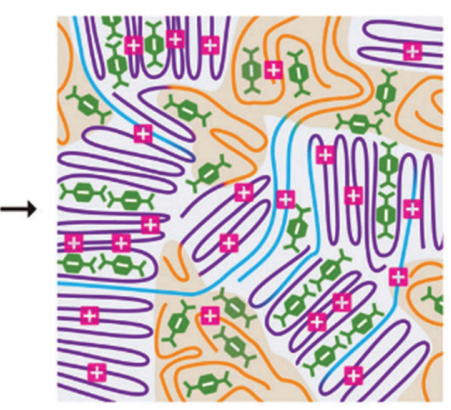

Sequential doping from CB allows F4TCNQ to infiltrate crystalline domains, increasing doping level but reducing doping efficiency, reducing conductivity

Figure 10 Schematic diagram of microstructure in mixed solution and sequential doping. Adapted with permission from Ref. 8c. Copyright 2016 The Royal Society of Chemistry.

F4TCNQ/P3HT was first spin-coated on substrates, and then soaked the F4TCNQ/P3HT blend films in the F4TCNQ dopant solution. Compared to the solution-blending method and sequential soaking method, hybrid doping can achieve whole-area doping for the crystalline and amorphous regions of polymer films. The expanded lamella distance in GIAWXS data and larger charge carrier migration region in c-AFM have been demonstrated, indicating the effective dopant diffusion into the polymer chain network and dopant migration across almost the whole film region. This method overcomes the problems of the insoluble polymer/dopant complex owing to the strong interactions in the solution-blending method and diffusion limitation of dopants into the crystalline domain in the sequential soaking method. The improvement of different processing methods is designed to allow more dopants to penetrate into the polymer films but minimize the impact on the crystalline domains as much as possible.

\section{Conclusions and Outlook}

The introduction of dopants in conjugated polymers will not only increase the charge carrier concentrations but also damage the microstructure of intrinsic polymer films, thereby affecting the final performance. In this review, some characteristic methods that are used to analyze the surface morphology, the microstructure of crystalline domains, and the phase separation of polymer films are discussed. Several strategies, such as optimizing the backbone structure of polymers and dopants, and suitable processing methods, which are used to modulate the microstructure and obtain higher conductivity, are summarized. These strategies have been widely applied in more and more conductive polymer materials.

Polymers frequently have imperfect ordering structure in thin films, so that the electronic structure depends strongly on their microstructure. The conductivity of polymers $(\sigma)$ is related to the charge carrier concentration 
( $n$ ) and mobility $(\mu)$. The carrier concentration is determined by the introduced dopants, which can also affect the structure disorder of the film, while $\mu$ is influenced by the degree of electronic and structural disorder. The doped polymer films include high concentrations dopants, which can result in strong perturbations of the microstructure compared to pristine films. The final performance the doped films have a very important relationship with the microstructure of the films.

In conductive polymer films, due to the complex chemical reaction during doping and the fuzzy reaction mechanisms, it is difficult to figure out the final products after doping. ${ }^{52}$ So, we can hardly make the connection with the morphology and the distribution of products. In addition, how to measure the miscibility and interactions between dopants and polymer, and determine the distribution location of dopants, and balance the increased charge carriers and decreased mobility when doping, are very challenging in the field of conductive polymers. Some researchers use computational methods to simulate the interactions between dopants and polymers in doping systems; however, the theoretical method is not very accurate and perfect, which needs more considerations. ${ }^{53}$ In the future, some efforts should be focused on better understanding of the chemical and physical interactions, and the specific distribution of dopants in solid films, which can help us figure out the relationship between morphology and performance.

\section{Funding Information}

This work is supported by the National Key R\&D Program of China (2017YFA0204701) and the National Natural Science Foundation of China (21790260, 21722201).

\section{References}

(1) Lee, S.; Kwon, J. H.; Kwon, S.; Choi, K. C. IEEE Trans. Electron Devices 2017, 64, 1922.

(2) (a) Allard, S.; Forster, M.; Souharce, B.; Thiem, H.; Scherf, U. Angew. Chem. Int. Ed. 2008, 47, 4070. (b) Di, C. A.; Zhang, F.; Zhu, D. Adv. Mater. 2013, 25, 313 .

(3) (a) Bubnova, O.; Crispin, X. Energy Environ. Sci. 2012, 5, 9345. (b) Culebras, M.; Gómez, C. M.; Cantarero, A. Materials 2014, 7, 6701. (c) Poehler, T. O.; Katz, H. E. Energy Environ. Sci. 2012, 5, 8110. (d) Russ, B.; Glaudell, A.; Urban, J. J.; Chabinyc, M. L.; Segalman, R. A. Nat. Rev. Mater. 2016, 1, 16050. (e) Yang, J.; Yip, H.-L.; Jen, A. K.-Y. Adv. Energy Mater. 2013, 3, 549. (f) Zhao, W.; Ding, J.; Zou, Y.; Di, C. A.; Zhu, D. Chem. Soc. Rev. 2020, 49, 7210.

(4) (a) Chen, Y.; Zhao, Y.; Liang, Z. Energy Environ. Sci. 2015, 8, 401. (b) Zhang, Q.; Sun, Y.; Xu, W.; Zhu, D. Adv. Mater. 2014, 26, 6829.

(5) Kim, G. H.; Shao, L.; Zhang, K.; Pipe, K. P. Nat. Mater. 2013, 12, 719.

(6) (a) Ferhat, S.; Domain, C.; Vidal, J.; Noël, D.; Ratier, B.; Lucas, B. Sustainable Energy Fuels 2018, 2, 199. (b) We, J. H.; Kim, S. J.; Cho,
B. J. Energy 2014, 73, 506. (c) Zhang, B.; Sun, J.; Katz, H. E.; Fang, F.; Opila, R. L. ACS Appl. Mater. Interfaces 2010, 2, 3170.

(7) (a) Kim, D.; Kim, Y.; Choi, K.; Grunlan, J. C.; Yu, C. ACS Nano 2010, 4, 513. (b) Yu, C.; Choi, K.; Yin, L.; Grunlan, J. C. ACS Nano 2011, 5, 7885.

(8) (a) Gao, J.; Niles, E. T.; Grey, J. K. J. Phys. Chem. Lett. 2013, 4, 2953. (b) Gao, J.; Stein, B. W.; Thomas, A. K.; Garcia, J. A.; Yang, J.; Kirk, M. L.; Grey, J. K. J. Phys. Chem. C 2015, 119, 16396. (c) Jacobs, I. E.; Aasen, E. W.; Oliveira, J. L.; Fonseca, T. N.; Roehling, J. D.; Li, J.; Zhang, G.; Augustine, M. P.; Mascal, M.; Moulé, A. J. J. Mater. Chem. C 2016, 4, 3454. (d) Kang, K.; Watanabe, S.; Broch, K.; Sepe, A.; Brown, A.; Nasrallah, I.; Nikolka, M.; Fei, Z.; Heeney, M.; Matsumoto, D.; Marumoto, K.; Tanaka, H.; Kuroda, S.; Sirringhaus, H. Nat. Mater. 2016, 15, 896. (e) Maennig, B.; Pfeiffer, M.; Nollau, A.; Zhou, X.; Leo, K.; Simon, P. Phys. Rev. B: Condens. Matter 2001, 64, 195208. (f) Pingel, P.; Neher, D. Phys. Rev. B: Condens. Matter 2013, 87, 115209.

(9) (a) Jacobs, I. E.; Cendra, C.; Harrelson, T. F.; Bedolla Valdez, Z. I.; Faller, R.; Salleo, A.; Moulé, A. J. Mater. Horiz. 2018, 5, 655. (b) Zheng, Y.-Q.; Yao, Z.-F.; Lei, T.; Dou, J.-H.; Yang, C.-Y.; Zou, L.; Meng, X.; Ma, W.; Wang, J.-Y.; Pei, J. Adv. Mater. 2017, 29, 1701072.

(10) Rivnay, J.; Mannsfeld, S. C. B.; Miller, C. E.; Salleo, A.; Toney, M. F. Chem. Rev. 2012, 112, 5488.

(11) (a) Kang, S. D.; Snyder, G. J. Nat. Mater. 2016, 16, 252. (b) Noriega, R.; Rivnay, J.; Vandewal, K.; Koch, F. P. V.; Stingelin, N.; Smith, P.; Toney, M. F.; Salleo, A. Nat. Mater. 2013, 12, 1038.

(12) (a) Boyle, C. J.; Upadhyaya, M.; Wang, P.; Renna, L. A.; Lu-Díaz, M.; Pyo Jeong, S.; Hight-Huf, N.; Korugic-Karasz, L.; Barnes, M. D.; Aksamija, Z.; Venkataraman, D. Nat. Commun. 2019, 10, 2827. (b) Fontana, M. T.; Stanfield, D. A.; Scholes, D. T.; Winchell, K. J.; Tolbert, S. H.; Schwartz, B. J.J. Phys. Chem. C 2019, 123, 22711. (c) Kang, K.; Schott, S.; Venkateshvaran, D.; Broch, K.; Schweicher, G.; Harkin, D.; Jellett, C.; Nielsen, C. B.; McCulloch, I.; Sirringhaus, H. Mater. Today Phys. 2019, 8, 112. (d) Lim, E.; Peterson, K. A.; Su, G. M.; Chabinyc, M. L. Chem. Mater. 2018, 30, 998. (e) Patel, S. N.; Glaudell, A. M.; Peterson, K. A.; Thomas, E. M.; O'Hara, K. A.; Lim, E.; Chabinyc, M. L. Sci. Adv. 2017, 3, e1700434. (f) Sun, Y.; Di, C.A.; Xu, W.; Zhu, D. Adv. Electron. Mater. 2019, 5, 1800825.

(13) (a) Mazaheripour, A.; Thomas, E. M.; Segalman, R. A.; Chabinyc, M. L. Macromolecules 2019, 52, 2203. (b) Steyrleuthner, R.; Schubert, M.; Howard, I.; Klaumünzer, B.; Schilling, K.; Chen, Z.; Saalfrank, P.; Laquai, F.; Facchetti, A.; Neher, D. J. Am. Chem. Soc. 2012, 134, 18303. (c) Wang, Z.-Y.; Yao, Z.-F.; Lu, Y.; Ding, L.; Yu, Z.-D.; You, H.-Y.; Wang, X.-Y.; Zhou, Y.-Y.; Zou, L.; Wang, J.-Y.; Pei, J. Polym. Chem. 2020, 11, 3716. (d) Yao, Z.-F.; Wang, Z.-Y.; Wu, H.T.; Lu, Y.; Li, Q.-Y.; Zou, L.; Wang, J.-Y.; Pei, J. Angew. Chem. Int. Ed. 2020, 59, 17467.

(14) Wang, Y.; Yang, L.; Shi, X. L.; Shi, X.; Chen, L.; Dargusch, M. S.; Zou, J.; Chen, Z. G. Adv. Mater. 2019, 31, 1807916.

(15) (a) Coropceanu, V.; Cornil, J.; da Silva Filho, D. A.; Olivier, Y.; Silbey, R.; Brédas, J.-L. Chem. Rev. 2007, 107, 926. (b) Noriega, R.; Rivnay, J.; Vandewal, K.; Koch, F. P. V.; Stingelin, N.; Smith, P.; Toney, M. F.; Salleo, A. Nat. Mater. 2013, 12, 1038. (c) Rivnay, J.; Jimison, L. H.; Northrup, J. E.; Toney, M. F.; Noriega, R.; Lu, S.; Marks, T. J.; Facchetti, A.; Salleo, A. Nat. Mater. 2009, 8, 952.

(16) Venkateshvaran, D.; Nikolka, M.; Sadhanala, A.; Lemaur, V.; Zelazny, M.; Kepa, M.; Hurhangee, M.; Kronemeijer, A. J.; Pecunia, V.; Nasrallah, I.; Romanov, I.; Broch, K.; McCulloch, I.; Emin, D.; Olivier, Y.; Cornil, J.; Beljonne, D.; Sirringhaus, H. Nature 2014, 515, 384. 
(17) Naab, B. D.; Gu, X.; Kurosawa, T.; To, J. W. F.; Salleo, A.; Bao, Z. Adv. Electron. Mater. 2016, 2, 1600004.

(18) (a) Liu, J.; Qiu, L.; Alessandri, R.; Qiu, X.; Portale, G.; Dong, J.; Talsma, W.; Ye, G.; Sengrian, A. A.; Souza, P. C. T.; Loi, M. A.; Chiechi, R. C.; Marrink, S. J.; Hummelen, J. C.; Koster, L. J. A. Adv. Mater. 2018, 30, 1704630. (b) Yang, C.-Y.; Jin, W.-L.; Wang, J.; Ding, Y.-F.; Nong, S.; Shi, K.; Lu, Y.; Dai, Y.-Z.; Zhuang, F.-D.; Lei, T.; Di, C.-A.; Zhu, D.; Wang, J.-Y.; Pei, J. Adv. Mater. 2018, 30, 1802850.

(19) (a) Gao, J.; Roehling, J. D.; Li, Y.; Guo, H.; Moulé, A. J.; Grey, J. K. J. Mater. Chem. C 2013, 1, 5638. (b) Li, M.; Balawi, A. H.; Leenaers, P. J.; Ning, L.; Heintges, G. H. L.; Marszalek, T.; Pisula, W.; Wienk, M. M.; Meskers, S. C. J.; Yi, Y.; Laquai, F.; Janssen, R. A. J. Nat. Commun. 2019, 10, 2867. (c) Yao, Z.-F.; Zheng, Y.-Q.; Li, Q.-Y.; Lei, T.; Zhang, S.; Zou, L.; Liu, H.-Y.; Dou, J.-H.; Lu, Y.; Wang, J.-Y.; Gu, X.; Pei, J. Adv. Mater. 2018, 31, 1806747.

(20) (a)Cochran,J.E.; Junk, M.J.N.; Glaudell, A. M.; Miller, P. L.; Cowart,J. S.; Toney, M. F.; Hawker, C. J.; Chmelka, B. F.; Chabinyc, M. L. Macromolecules 2014, 47, 6836. (b) Salzmann, I.; Heimel, G.; Oehzelt, M.; Winkler, S.; Koch, N. Acc. Chem. Res. 2016, 49, 370.

(21) Yan, X.; Xiong, M.; Li, J.-T.; Zhang, S.; Ahmad, Z.; Lu, Y.; Wang, Z.Y.; Yao, Z.-F.; Wang, J.-Y.; Gu, X.; Lei, T. J. Am. Chem. Soc. 2019, 141, 20215.

(22) (a) Méndez, H.; Heimel, G.; Winkler, S.; Frisch, J.; Opitz, A.; Sauer, K.; Wegner, B.; Oehzelt, M.; Röthel, C.; Duhm, S.; Többens, D.; Koch, N.; Salzmann, I. Nat. Commun. 2015, 6, 8560. (b) Salzmann, I.; Heimel, G.; Duhm, S.; Oehzelt, M.; Pingel, P.; George, B. M.; Schnegg, A.; Lips, K.; Blum, R.-P.; Vollmer, A.; Koch, N. Phys. Rev. Lett. 2012, 108, 035502. (c) Tietze, M. L.; Benduhn, J.; Pahner, P.; Nell, B.; Schwarze, M.; Kleemann, H.; Krammer, M.; Zojer, K.; Vandewal, K.; Leo, K. Nat. Commun. 2018, 9, 1182.

(23) Binnig, G.; Quate, C. F.; Gerber, C. Phys. Rev. Lett. 1986, 56, 930.

(24) (a) Sahin, O.; Magonov, S.; Su, C.; Quate, C. F.; Solgaard, O. Nat. Nanotechnol. 2007, 2, 507. (b) Villarrubia, J. S. J. Res. Natl. Inst. Stand. Technol. 1997, 102, 425.

(25) (a) Dazzi, A.; Prater, C. B.; Hu, Q.; Chase, D. B.; Rabolt, J. F.; Marcott, C. Appl. Spectrosc. 2012, 66, 1365. (b) Dazzi, A.; Prazeres, R.; Glotin, F.; Ortega, J. M. Opt. Lett. 2005, 30, 2388.

(26) (a) Lu, F.; Belkin, M. A. Opt. Express 2011, 19, 19942. (b) Lu, F.; Jin, M.; Belkin, M. A. Nat. Photonics 2014, 8, 307.

(27) Pingree, L. S. C.; Reid, O. G.; Ginger, D. S. Adv. Mater. 2009, 21, 19.

(28) (a) Liscio, A.; Palermo, V.; Samorì, P. Adv. Funct. Mater. 2008, 18, 907. (b) Melitz, W.; Shen, J.; Kummel, A. C.; Lee, S. Surf. Sci. Rep. 2011, 66, 1 .

(29) Jenkins, J. L.; Lee, P. A.; Nebesny, K. W.; Ratcliff, E. L. J. Mater. Chem. A 2014, 2, 19221.

(30) Tsao, H. N.; Cho, D.; Andreasen, J. W.; Rouhanipour, A.; Breiby, D. W.; Pisula, W.; Müllen, K. Adv. Mater. 2009, 21, 209.

(31) Baker, J. L.; Jimison, L. H.; Mannsfeld, S.; Volkman, S.; Yin, S.; Subramanian, V.; Salleo, A.; Alivisatos, A. P.; Toney, M. F. Langmuir 2010, 26, 9146.

(32) Ma, W.; Shi, K.; Wu, Y.; Lu, Z.-Y.; Liu, H.-Y.; Wang, J.-Y.; Pei, J. ACS Appl. Mater. Interfaces 2016, 8, 24737.

(33) (a) Ma, W.; Tumbleston, J. R.; Wang, M.; Gann, E.; Huang, F.; Ade, H. Adv. Energy Mater. 2013, 3, 864. (b) Ma, W.; Tumbleston, J. R.; Ye, L.; Wang, C.; Hou, J.; Ade, H. Adv. Mater. 2014, 26, 4234.

(34) (a) Kiefer, D.; Giovannitti, A.; Sun, H.; Biskup, T.; Hofmann, A.; Koopmans, M.; Cendra, C.; Weber, S.; Anton Koster, L. J.; Olsson, E.; Rivnay, J.; Fabiano, S.; McCulloch, I.; Müller, C. ACS Energy Lett. 2018, 3, 278. (b) Liu, J.; Ye, G.; Zee, B. d.; Dong, J.; Qiu, X.; Liu, Y.; Portale, G.; Chiechi, R. C.; Koster, L. J. A. Adv. Mater. 2018, 30,
1804290. (c) Mai, C.-K.; Schlitz, R. A.; Su, G. M.; Spitzer, D.; Wang, X.; Fronk, S. L.; Cahill, D. G.; Chabinyc, M. L.; Bazan, G. C. J. Am. Chem. Soc. 2014, 136, 13478. (d) Shin, Y.; Massetti, M.; Komber, H.; Biskup, T.; Nava, D.; Lanzani, G.; Caironi, M.; Sommer, M. Adv. Electron. Mater. 2018, 4, 1700581. (e) Wang, S.; Fazzi, D.; Puttisong, Y.; Jafari, M. J.; Chen, Z.; Ederth, T.; Andreasen, J. W.; Chen, W. M.; Facchetti, A.; Fabiano, S. Chem. Mater. 2019, 31, 3395. (f) Wang, S.; Sun, H.; Erdmann, T.; Wang, G.; Fazzi, D.; Lappan, U.; Puttisong, Y.; Chen, Z.; Berggren, M.; Crispin, X.; Kiriy, A.; Voit, B.; Marks, T. J.; Fabiano, S.; Facchetti, A. Adv. Mater. 2018, 30, 1801898.

(35) Schlitz, R. A.; Brunetti, F. G.; Glaudell, A. M.; Miller, P. L.; Brady, M. A.; Takacs, C. J.; Hawker, C. J.; Chabinyc, M. L. Adv. Mater. 2014, 26, 2825.

(36) Perry, E. E.; Chiu, C.-Y.; Moudgil, K.; Schlitz, R. A.; Takacs, C. J.; O'Hara, K. A.; Labram, J. G.; Glaudell, A. M.; Sherman, J. B.; Barlow, S.; Hawker, C. J.; Marder, S. R.; Chabinyc, M. L. Chem. Mater. 2017, 29, 9742.

(37) Shin, Y.; Massetti, M.; Komber, H.; Biskup, T.; Nava, D.; Lanzani, G.; Caironi, M.; Sommer, M. Adv. Electron. Mater. 2018, 4, 1700581.

(38) Yuan, D.; Huang, D.; Rivero, S. M.; Carreras, A.; Zhang, C.; Zou, Y.; Jiao, X.; McNeill, C. R.; Zhu, X.; Di, C.-a.; Zhu, D.; Casanova, D.; Casado, J. Chem 2019, 5, 964.

(39) Ding, J.; Liu, Z.; Zhao, W.; Jin, W.; Xiang, L.; Wang, Z.; Zeng, Y.; Zou, Y.; Zhang, F.; Yi, Y.; Diao, Y.; McNeill, C. R.; Di, C.-a.; Zhang, D.; Zhu, D. Angew. Chem. Int. Ed. 2019, 58, 18994.

(40) (a) Li, J.; Rochester, C. W.; Jacobs, I. E.; Aasen, E. W.; Friedrich, S.; Stroeve, P.; Moulé, A. J. Org. Electron. 2016, 33, 23. (b) Liang, Z.; Zhang, Y.; Souri, M.; Luo, X.; Boehm, A. M.; Li, R.; Zhang, Y.; Wang, T.; Kim, D.-Y.; Mei, J.; Marder, S. R.; Graham, K. R. J. Mater. Chem. A 2018, 6, 16495. (c) Tietze, M. L.; Pahner, P.; Schmidt, K.; Leo, K.; Lüssem, B. Adv. Funct. Mater. 2015, 25, 2701.

(41) Un, H.-I.; Gregory, S. A.; Mohapatra, S. K.; Xiong, M.; Longhi, E.; Lu, Y.; Rigin, S.; Jhulki, S.; Yang, C.-Y.; Timofeeva, T. V.; Wang, J.Y.; Yee, S. K.; Barlow, S.; Marder, S. R.; Pei, J. Adv. Energy Mater. 2019, 9, 1900817.

(42) Yang, C.-Y.; Ding, Y.-F.; Huang, D.; Wang, J.; Yao, Z.-F.; Huang, C.X.; Lu, Y.; Un, H.-I.; Zhuang, F.-D.; Dou, J.-H.; Di, C. A.; Zhu, D.; Wang, J.-Y.; Lei, T.; Pei, J. Nat. Commun. 2020, 11, 3292.

(43) (a) Lu, Y.; Yu, Z.-D.; Liu, Y.; Ding, Y.-F.; Yang, C.-Y.; Yao, Z.-F.; Wang, Z.-Y.; You, H.-Y.; Cheng, X.-F.; Tang, B.; Wang, J.-Y.; Pei, J.J. Am. Chem. Soc. 2020, 142, 15340. (b) Shi, K.; Lu, Z.-Y.; Yu, Z.-D.; Liu, H.-Y.; Zou, Y.; Yang, C.-Y.; Dai, Y.-Z.; Lu, Y.; Wang, J.-Y.; Pei, J. Adv. Electron. Mater. 2017, 3, 1700164.

(44) Zhang, Y.; de Boer, B.; Blom, P.W.M.Adv. Funct. Mater. 2009, 19, 1901.

(45) (a) Aziz, E. F.; Vollmer, A.; Eisebitt, S.; Eberhardt, W.; Pingel, P.; Neher, D.; Koch, N. Adv. Mater. 2007, 19, 3257. (b) Karpov, Y.; Erdmann, T.; Raguzin, I.; Al-Hussein, M.; Binner, M.; Lappan, U.; Stamm, M.; Gerasimov, K. L.; Beryozkina, T.; Bakulev, V.; Anokhin, D. V.; Ivanov, D. A.; Günther, F.; Gemming, S.; Seifert, G.; Voit, B.; Di Pietro, R.; Kiriy, A. Adv. Mater. 2016, 28, 6003.

(46) Jha, A.; Duan, H.-G.; Tiwari, V.; Thorwart, M.; Miller, R. J. D. Chem. Sci. 2018, 9, 4468.

(47) Jacobs, I. E.; Li, J.; Burg, S. L.; Bilsky, D. J.; Rotondo, B. T.; Augustine, M. P.; Stroeve, P.; Moulé, A. J. ACS Nano 2015, 9, 1905.

(48) Kroon, R.; Mengistie, D. A.; Kiefer, D.; Hynynen, J.; Ryan, J. D.; Yu, L.; Müller, C. Chem. Soc. Rev. 2016, 45, 6147.

(49) (a) Ingram, I. D. V.; Tate, D. J.; Parry, A. V. S.; Sprick, R. S.; Turner, M. L. Appl. Phys. Lett. 2014, 104, 153304. (b) Scholes, D. T.; 
Organic Materials

Hawks, S. A.; Yee, P. Y.; Wu, H.; Lindemuth, J. R.; Tolbert, S. H.; Schwartz, B. J. J. Phys. Chem. Lett. 2015, 6, 4786.

(50) Hwang, S.; Potscavage, W. J.; Yang, Y. S.; Park, I. S.; Matsushima, T.; Adachi, C. Phys. Chem. Chem. Phys. 2016, 18, 29199.

(51) Yoon, S. E.; Kang, Y.; Jeon, G. G.; Jeon, D.; Lee, S. Y.; Ko, S.-J.; Kim, T.; Seo, H.; Kim, B.-G.; Kim, J. H. Adv. Funct. Mater. 2020, 30, 2004598.

(52) (a) Naab, B. D.; Guo, S.; Olthof, S.; Evans, E. G. B.; Wei, P.; Millhauser, G. L.; Kahn, A.; Barlow, S.; Marder, S. R.; Bao, Z. J. Am.
Chem. Soc. 2013, 135, 15018. (b) Wei, P.; Oh, J. H.; Dong, G.; Bao, Z. J. Am. Chem. Soc. 2010, 132, 8852. (c) Yurash, B.; Cao, D. X.; Brus, V. V.; Leifert, D.; Wang, M.; Dixon, A.; Seifrid, M.; Mansour, A. E.; Lungwitz, D.; Liu, T.; Santiago, P. J.; Graham, K. R.; Koch, N.; Bazan, G. C.; Nguyen, T.-Q. Nat. Mater. 2019.

(53) (a) Körzdörfer, T.; Brédas, J.-L. Acc. Chem. Res. 2014, 47, 3284. (b) Shi, W.; Wang, D.; Shuai, Z. Adv. Electron. Mater. 2019, 5, 1800882 . 